\title{
A Worldwide Survey of the Current Daily Practice in Liver Surgery
}

\author{
Yoshihiro Mise Yoshihiro Sakamoto Takeaki Ishizawa Junichi Kaneko \\ Taku Aoki Kiyoshi Hasegawa Yasuhiko Sugawara Norihiro Kokudo \\ Hepato-Biliary-Pancreatic Surgery Division, Department of Surgery, Graduate School of \\ Medicine, University of Tokyo, Tokyo, Japan
}

\section{Key Words}

Liver function $\cdot$ Liver volume $\cdot$ Liver resection $\cdot$ Laparoscopic hepatectomy

\begin{abstract}
Background: Liver resection remains the mainstay of curative treatment for liver malignancies. A variety of preoperative assessments and surgical techniques have improved the shortand long-term outcomes of liver resection in patients with liver tumors. Recently, laparoscopic hepatectomies have been increasingly performed. The aim of the present study is to survey the current practice of liver surgery in high-volume centers in the world. Methods: A questionnaire on the preoperative assessment for liver surgery, open hepatectomy, and laparoscopic hepatectomy was sent to 94 liver centers in the world. Results: Forty-two centers (45\%) responded to this survey (29 Asian, 9 European, and 4 North American centers). All but one of the centers evaluated the future liver remnant (FLR) volume, and $95 \%$ of them performed preoperative portal vein embolization to increase the FLR volume. In half of the centers, the required FLR volume was over $30 \%$ in patients with normal liver and $50 \%$ in patients with cirrhotic liver. To reduce the intraoperative blood loss, half of the centers routinely used Pringle's maneuver, and $85 \%$ restricted the intraoperative fluid infusion to reduce the central venous pressure. More than 10 laparoscopic hepatectomies were performed per year in $62 \%$ of the centers, and more than 30 were performed in $26 \%$, respectively. Laparoscopic major hepatectomies were performed in $24 \%$. Two-thirds answered that the laparoscopic approach would be feasible in donor hepatectomy. Conclusion: The evaluation of FLR volume in patients with normal or cirrhotic liver and the usage of preoperative portal vein embolization have become essential practice in more than $90 \%$ of the centers. Reduced blood loss has been achieved using Pringle's maneuver, restriction of fluid infusion, and a variety of surgical devises. The laparoscopic approach is increasingly extended to major hepatectomy or donor hepatectomy.
\end{abstract}


Mise et al.: A Worldwide Survey of the Current Daily Practice in Liver Surgery

\section{Introduction}

Liver resection represents the mainstay of curative treatment for hepatic malignancies. Recent progress in preoperative assessments and refinements in surgical techniques have dramatically improved the safety and prognostic outcomes of liver surgery over the past two decades. One of the major concerns for liver surgeons is how to evaluate the functional reserve especially in patients with underlying liver damage due to viral hepatitis, steatosis, or chemotherapeutic agents. There has been a variety of liver function tests and grading systems reported in the literature [1-6]. In a previous survey conducted by Breitenstein et al. [7] in 2007, a wide diversity in the application of liver function tests and in the minimal future liver remnant (FLR) volume to be preserved was demonstrated among centers as well as continents. Therefore, it will be meaningful to know the trend of the preoperative assessment to maintain the safety of liver resection toward the year 2012 .

A number of surgical devices and techniques for liver resection have been developed in order to reduce the intraoperative blood loss [8-23]. It has been reported that the amount of intraoperative blood loss was associated with the incidence of surgical complications [24, 25], and perioperative blood transfusion have been shown to increase the recurrence rate of liver malignancies after surgical treatment [26]. Several studies have searched an advantage of one surgical device or techniques over others to reduce intraoperative blood loss [9-15]. However, only one study has assessed the trend of the devices and techniques used during liver surgery [27].

On the other hand, the recent wave of the laparoscopic approach has reached to the field of liver resection, which is further diversifying the daily practice of liver surgeons. This survey aimed to address the current trend in liver surgery all over the world, focusing on 3 topics: preoperative assessment, procedures in open hepatectomy, and laparoscopic liver resection.

\section{Methods}

Ninety-four leading hepato-pancreato-biliary centers around the world were invited to participate in this survey in July 2012 (72 Asian, 13 European, and 9 North American centers). These centers were selected on the basis of academic achievements and the personal contacts through international conferences. A questionnaire was sent to the centers by e-mail, with a cover letter calling for participation. The survey was closed in October 2012.

The number of open and laparoscopic liver resections performed in each center per year was filled in at the beginning of the questionnaire. The main questionnaire focused on the following 3 topics to evaluate the current practices in liver surgery: preoperative assessment of liver function and FRL volume, procedures and devices used in open liver surgery, and indications and devices applied in laparoscopic liver surgery (tables 1-3).

The derived data are expressed as medians with ranges. The best answer was to be selected in each question, but some centers selected several choices. Hence, the results are demonstrated as the total number of all answers.

\section{Results}

Forty-two centers (45\%) responded to the survey (29 Asian, 9 European, and 4 North American centers). The total number of liver resections per year was 125 (30-785), and the number of open liver resections per year was 100 (8-700). One-quarter of the centers performed less than 50 liver resections per year, and another one-quarter performed more than 150 liver resections. 
Table 1. Questionnaire on the preoperative assessment of liver function and FLR volume

1 In the preoperative assessment of liver function reserve, which grading system do you use?
a. Child-Pugh score
b. ICGR15 test
c. Presence or absence of portal hypertension
d. MELD score
e. Others, please describe

2 Do you evaluate the FLR volume by CT volumetry?
a. Yes, only before hemihepatectomy
b. Yes, before segmentectomy or hemihepatectomy
c. No

3 Do you perform preoperative PVE before hepatectomy?
a. Yes, based on the balance between the hepatic function and the FRL volume calculated by CT volumetry
b. Yes, only before right hemihepatectomy or trisectoriectomy (trisegmentectomy)
c. No
d. Others, please describe

4 Which percentage of FRL volume do you accept without PVE in patients with normal liver function?
a. $20 \%$
b. $25 \%$
c. $30 \%$
d. $35 \%$
e. $40 \%$

5 Which percentage of FRL volume do you accept without PVE in patients with impaired liver function?
a. $30 \%$ or less
b. $35 \%$
c. $40 \%$
d. $45 \%$
e. $50 \%$ or more

The number of laparoscopic liver resections per year was 14 (0-100). One-quarter of the centers performed more than 30 laparoscopic liver resections. Five centers $(12 \%, 4$ Asian centers and 1 European center) did not adopt the laparoscopic approach in liver surgery. The correlation between the number of open and laparoscopic liver resections is shown in figure 1.

\section{Preoperative Assessment of Liver Function and FLR Volume (fig. 2)}

Liver Function

To estimate the preoperative liver function, 31 centers (74\%, 25 Asian and 6 European centers) adopted the indocyanine green retention test at $15 \mathrm{~min}$ (ICGR15). Only 1 out of the 25 Japanese centers did not choose ICGR15 as the preoperative assessment modality. The Child-Pugh score was used in 14 centers (33\%, 7 Asian, 5 European, and 2 North American centers). The presence of portal hypertension was taken into account in 7 centers $(17 \%, 3$ Asian and 3 European centers as well as 1 North American center). Two centers (1 European and 1 North American) used the model for end-stage liver disease (MELD) score as the sole preoperative assessment.

Volumetric Analysis

All but one of the centers evaluated the FLR volume using computed tomography (CT) volumetry. Twenty-one centers performed CT volumetry prior to segmentectomy or hemihepatectomy or more, and the remaining 20 centers assessed prior to hemihepatectomy or more, respectively. 
Table 2. Questionnaire on the procedures and devices used in open liver surgery

1 Do you perform vascular control by individually dissecting the hepatoduodenal ligaments or in the en bloc fashion by Takasaki et al.'s method [18] prior to division of liver parenchyma?

a. Individually hepatic artery, portal vein and the bile duct

b. En bloc ligation of the Glissonian sheath at the hepatic hilum

c. No

2 Do you apply intermittent Pringle's maneuver during division of the hepatic parenchyma?

a. Almost always

b. Sometimes (only when excessive bleeding occurs)

c. Rarely

d. No

3 Do you restrict the intraoperative fluid infusion to reduce the pressure of IVC?

a. Yes

b. No

4 How do you divide (not seal the portal pedicles) the hepatic parenchyma?
a. Clump-crushing
b. CUSA
c. Harmonic Scalpel
d. LigaSure
e. Linear stapler
f. Tissue Link
g. Bipolar scissors
h. Others, please describe

5 How do you seal the thin portal pedicles (less than $3 \mathrm{~mm}$ in diameter) or hepatic parenchyma?
a. Ligation with stitch
b. Harmonic Scalpel
c. LigaSure
d. Linear Stapler
e. Tissue Link
f. Bipolar scissors
g. Hemoclip
h. Others, please describe

6 Backflow from the hepatic veins is massive. How do you reduce blood loss?
a. Performing selective hepatic venous control
b. Performing total or half clamping IV
c. Performing total vascular exclusion
d. Blood drawing to reduce CVP
e. Head up or head down
f. Nothing special
g. Others, please describe

7 You need to reconstruct a thick hepatic vein. Which graft do you use?
a. External iliac vein graft
b. Prosthetic vein graft
c. Internal jugular vein
d. From gonadal vein, making a thick graft
e. From great saphenous vein, making a thick graft
f. Cryopreserved vein graft
g. Others, please describe 
Table 3. Questionnaire on the indications and devices applied in laparoscopic liver surgery

1 What is your 'current' indication for laparoscopic hepatectomy?

a. Left lateral segmentectomy and limited resection of the peripheral part of the liver

b. Major hepatectomies and/or for tumors in the posterior part of the liver (segment I/VII)

c. Others, please describe

2 What will be your 'future' indication for laparoscopic hepatectomy?

a. Left lateral segmentectomy and limited resection of the peripheral part of the liver

b. Major hepatectomies and/or for tumors in the posterior part of the liver (segment I/VII)

c. Others, please describe

3 Do you think the laparoscopic approach is acceptable for donor hepatectomy?
a. Yes
b. Yes, only for left lateral graft
c. No
d. Others, please describe

4 Do you apply intermittent Pringle's maneuver during division of the hepatic parenchyma?
a. Almost always
b. Sometimes (only when excessive bleeding occurs)
c. Rarely
d. No

5 How do you divide (not seal the portal pedicles) the hepatic parenchyma?
a. Clump-crushing
b. CUSA
c. Harmonic Scalpel
d. LigaSure
e. Linear stapler
f. Tissue Link
g. Bipolar scissors
h. Others, please describe

6 How do you seal the thin portal pedicles (less than $3 \mathrm{~mm}$ in diameter) or hepatic parenchyma?
a. Ligation with stitch
b. Harmonic Scalpel
c. LigaSure
d. Linear stapler
e. Tissue Link
f. Bipolar scissors
g. Hemoclip
h. Others, please describe

\section{Portal Vein Embolization}

Preoperative portal vein embolization (PVE) was performed to induce the compensatory hypertrophy of FLR in 40 centers $(95 \%)$ based on the results of the liver functional reserve and the extent of the liver resection.

In patients with normal liver function, 17 centers (40\%) set $30 \%$ of the total liver volume as the critical FLR volume for safe liver resection and performed PVE when the estimated FLR volume is less than $30 \%$. In patients with underlying cirrhosis, 18 centers (43\%) set less than $50 \%$ of the FLR volume as the critical volume requiring PVE. 


\section{Liver \\ Cancer}

Fig. 1. Correlation between the number of open and laparoscopic liver resections.

\begin{tabular}{l|l}
\hline Liver Cancer 2013;2:55-66 \\
\hline DOI: 10.1159/000346225 & $\begin{array}{l}\text { ( } 2013 \text { S. Karger AG, Basel } \\
\text { www.karger.com/lic }\end{array}$ \\
\hline Published online: January 7, 2013 &
\end{tabular}

Mise et al.: A Worldwide Survey of the Current Daily Practice in Liver Surgery

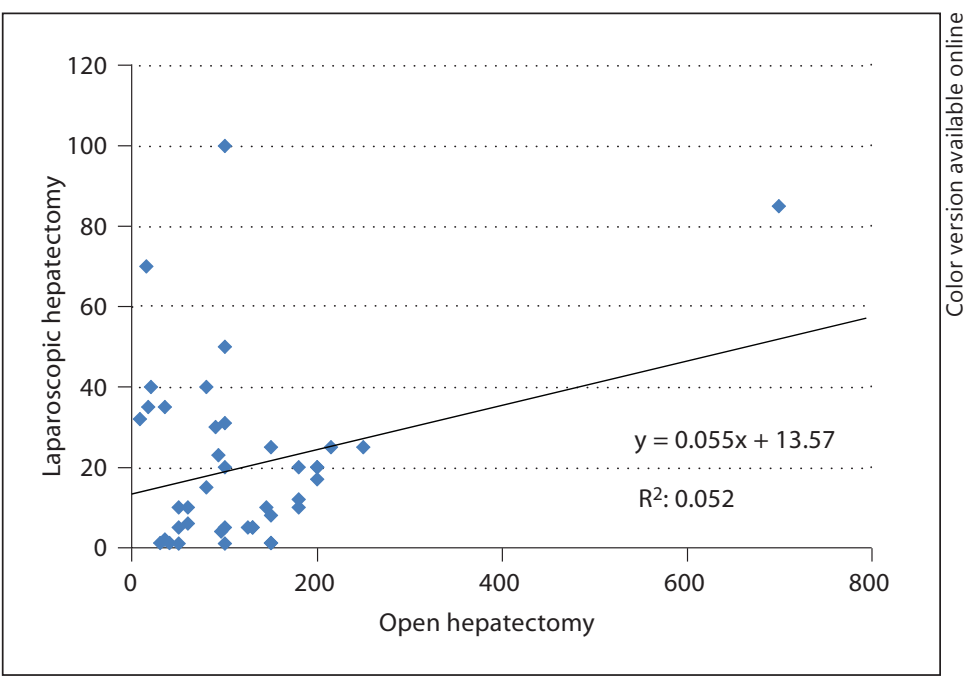

Q1. Assessment of liver function

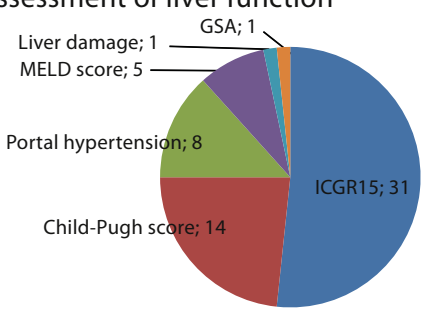

Q2. Application of volumetry

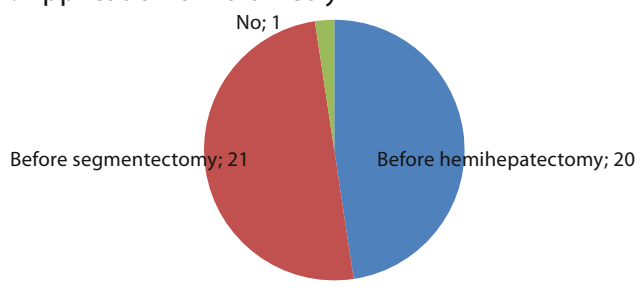

Q3. Portal vein embolization

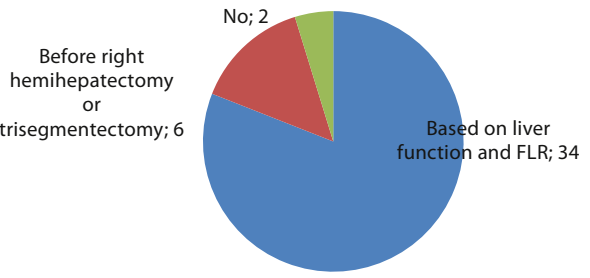

Q4. Critical FLR in normal liver

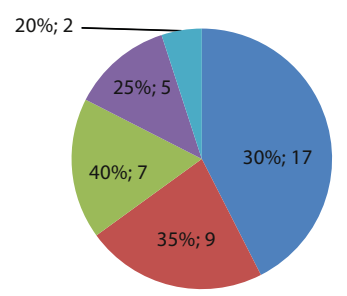

Q5. Critical FLR in cirrhotic liver

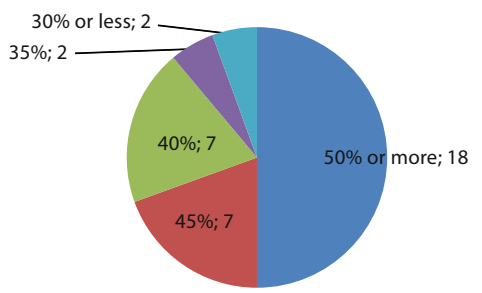

Fig. 2. Preoperative assessment of liver function and FLR volume. GSA = Galactosyl serum albumin scintigraphy. 


\section{Liver Cancer}

\begin{tabular}{l|l}
\hline Liver Cancer 2013;2:55-66 & \\
\hline DOI: 10.1159/000346225 & $\begin{array}{l}\text { ( ) 2013 S. Karger AG, Basel } \\
\text { www.karger.com/lic }\end{array}$ \\
\hline Published online: January 7, 2013 &
\end{tabular}

Mise et al.: A Worldwide Survey of the Current Daily Practice in Liver Surgery

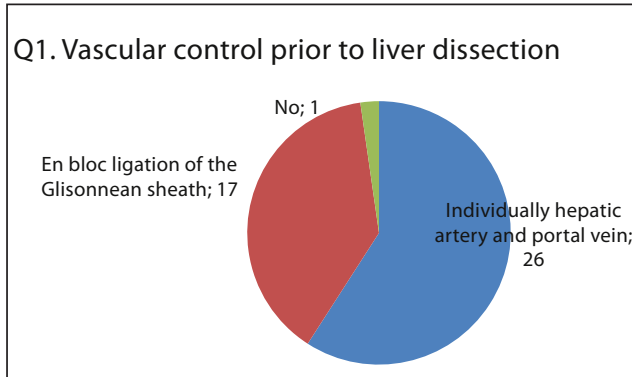

Q2. Application of Pringle's maneuver

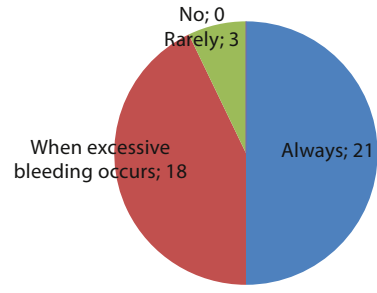

Q3. Restriction of fluid infusion

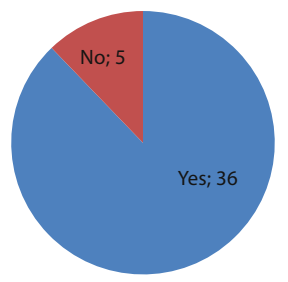

Q4. Devices for parenchymal division

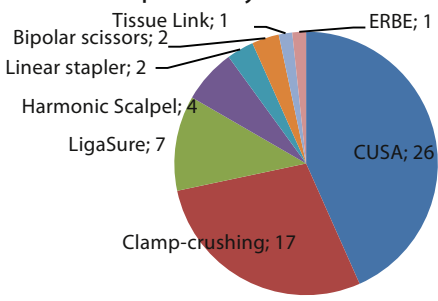

Q5. Devices to seal thin portal pedicles

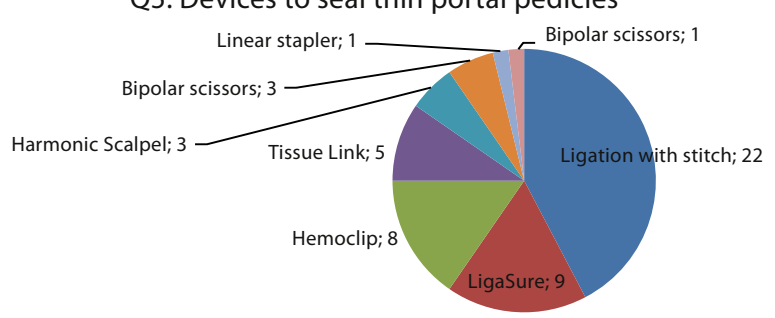

Q6. How to control the venous bleeding

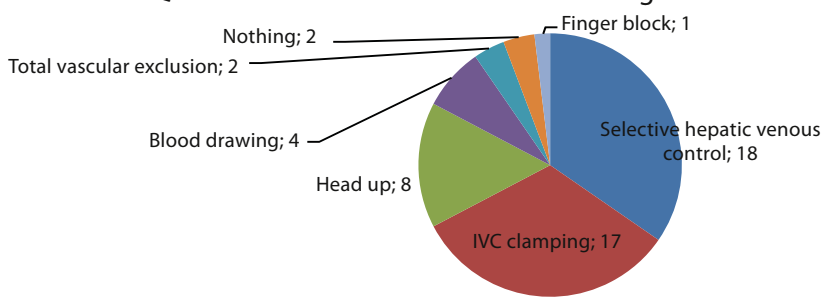

Q7. Graft for venous reconstruction

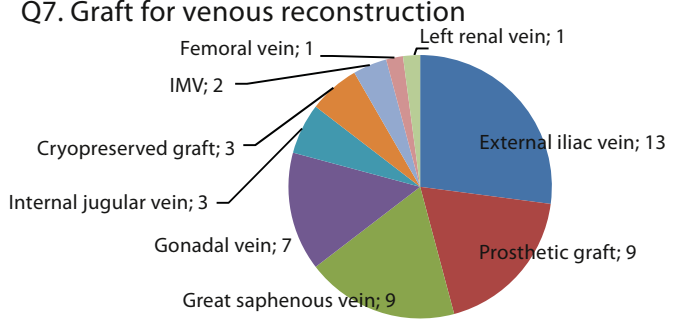

Fig. 3. Open hepatectomy.

\section{Open Hepatectomy (fig. 3)}

Surgical Devices Used during Liver Surgery

The most used device to divide the liver parenchyma was CUSA (26 centers, 62\%), followed by clamp-crushing methods (17 centers, $40 \%$ ). To seal the thin portal pedicles, half of the centers $(52 \%)$ used ligation with stitch. The second most used device was LigaSure ( 9 centers, 21\%).

\section{Inflow Control}

The vascular control prior to the division of the liver parenchyma was performed by individually ligating the hepatic artery and the portal vein in 23 centers (48\%), while 14 centers (33\%) used en bloc ligation of the Glissonian sheath at the hepatic hilum (Takasaki et al.'s method [18]). Pringle's maneuver was used routinely during the division of the liver parenchyma in 21 centers (50\%). Three centers (7\%) did not adopt the Pringle's maneuver. 


\section{Liver Cancer}

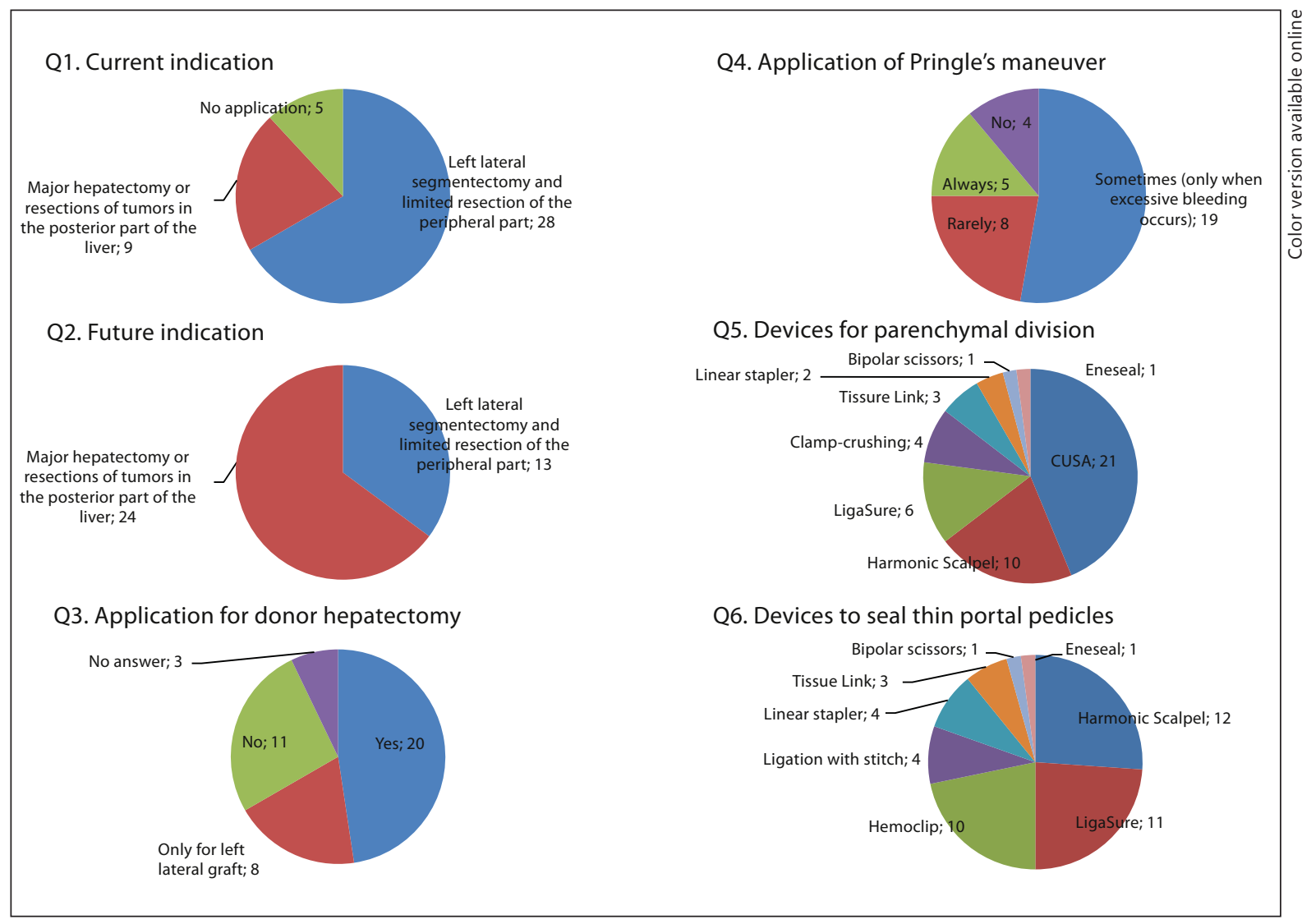

Fig. 4. Laparoscopic approach.

\section{Outflow Control}

Thirty-six centers (86\%) restricted the intraoperative fluid infusion to reduce the pressure in the inferior vena cava (IVC). In cases when venous bleeding was massive, 18 centers (43\%) performed selective hepatic venous control, and 17 centers (40\%) performed IVC clamping to reduce the blood loss.

\section{Venous Reconstruction}

The most often used graft for venous reconstruction was the external iliac vein (13 centers, 31\%). Both prosthetic graft and great saphenous vein were used in 9 centers each (21\%).

\section{Laparoscopic Approach (fig. 4)}

Indication

Thirty-seven centers (88\%) adopted laparoscopic liver resection, but the current indication was limited to left lateral segmentectomy or limited resection of the peripheral part of the liver in 28 of these 37 centers (76\%). The remaining 9 centers applied the laparoscopic approach to major hepatectomies or resections of tumors in the posterior part of the liver. In the future, 22 centers are willing to apply the laparoscopic approach to major hepatectomies or resection of tumors in the posterior part of the liver. Twenty-eight centers (67\%) answered that the laparoscopic approach is feasible for donor hepatectomy. 


\section{Liver Cancer}

\begin{tabular}{l|l}
\hline Liver Cancer 2013;2:55-66 & \\
\hline DOI: 10.1159/000346225 & $\begin{array}{l}\text { ( } 2013 \text { S. Karger AG, Basel } \\
\text { www.karger.com/lic }\end{array}$ \\
\hline Published online: January 7, 2013 &
\end{tabular}

Laparoscopic Procedures

Pringle's maneuver was used routinely only in 5 centers (12\%) during the laparoscopic approach. The most frequently used device to divide the liver parenchyma was CUSA [21 centers, 57\% (21/37)], followed by Harmonic Scalpel [10 centers, 27\% (10/37)]. To seal thin portal pedicles, Harmonic Scalpel, LigaSure, and Hemoclip were used in 12, 11, and 10 centers, respectively.

\section{Discussion}

The current survey provides an overview of the current practices of liver surgery, including the laparoscopic approach. The results show that many leading liver centers have applied detailed preoperative assessments and intraoperative procedures to reduce blood loss, and that the laparoscopic approach has been widely used in the world, holding the promise of being applied for the field of transplantation.

The evaluation of the resectional liver volume in patients with normal or cirrhotic liver and the application of PVE have become essential to achieve safe liver resection. The importance of assessing the FLR volume prior to liver resection has been emphasized in many reports because of the significant interpatient variation in liver volumes [28-33]. Lack of liver volume after hepatectomy was reportedly associated with an increased incidence of liver dysfunction not only in patients with cirrhotic liver but also in those with normal liver. In this survey, all but one out of the 45 centers evaluated the FLR volume prior to hemihepatectomy or segmentectomy to prevent postoperative liver failure. Moreover, $95 \%$ of the centers performed PVE to increase the FLR volume based on the results of liver function and FLR volume (81\%) and/or procedures of liver resection (12\%). The rate of the application of PVE (95\%) was higher than that reported in the survey conducted by Breitenstein et al. [7] in 2007 (89\%). The minimal FLR volume in normal liver was 30-40\% in $83 \%$ of the centers that answered the question. The critical limit of the FLR volume in this survey was higher than that in the previous survey [median 25\% (range 20-40\%)] [7]. The safe limit of the FLR volume might have interindividual differences; however, $40 \%$ of the FLR volume in normal liver would be a reliable criteria to achieve zero mortality following hepatectomy [34]. In practice, $30 \%$ is the standard in the world, although half of the centers answered that $50 \%$ of the FLR volume would be necessary in cirrhotic liver, which means that right hemihepatectomy cannot be safely performed in cirrhotic liver without preoperative PVE.

Reduction of intraoperative blood loss is a significant factor affecting the short- as well as long-term outcomes after liver resection [24-26]. Various intraoperative techniques have been widely applied to control the bleeding from both the inflow and outflow system. As for the inflow system, Pringle's maneuver and selective vascular occlusion can reduce the bleeding by limiting the blood flow to the liver $[16,17]$. Our survey demonstrated that most of the centers applied Pringle's maneuver routinely (50\%) or when excessive bleeding occurs $(43 \%)$ during open hepatectomy. On the other hand, the frequency of routine use of Pringle's maneuver decreased to $14 \%$ in the laparoscopic approach.

Bleeding from the outflow system is a major problem during complex liver resections because the backflow bleeding from the hepatic veins can occasionally be massive [22]. The survey reflects the high interest in the control of bleeding from the outflow system, and $88 \%$ of the centers restricted the intraoperative fluid infusion to reduce the central venous pressure. In cases of massive backflow from the hepatic veins, the most frequently used procedures were the control of selective hepatic veins (43\%) and IVC clamping (40\%). Recently, 2 prospective randomized controlled studies proved the efficacy of IVC clamping 
for reducing blood loss $[35,36]$. Total vascular exclusion, in which the infra- and suprahepatic IVCs are clamped, has been reported to be an effective procedure to achieve a bloodless liver resection [20,21]. However, this procedure is associated with significant hemodynamic changes and requires close monitoring to prevent central hypovolemia. Only 2 centers (5\%) applied total vascular exclusion to control backflow venous bleeding [23].

Our survey reflects the worldwide prevalence of laparoscopic liver resection and shows that $88 \%$ of the participating centers adapted the laparoscopic approach in liver surgery. Since the first introduction by Gagner et al. [37] in 1992, the application of laparoscopic liver resection has slowly progressed because of the complexity of liver surgery. Two meta-analyses demonstrated the benefits of the laparoscopic approach in terms of reduced operative blood loss and earlier recovery compared with open liver surgery [38, 39]. However, careful interpretation of the results derived from these meta-analyses is required in the light of potential selection bias. Most of the data were extracted from the comparison of the series of left lateral segmentectomy or partial resection of the liver, which accounted for a small part of the wide variety of hepatectomies. The results of this survey well reflect the careful attitude toward the current indications of the laparoscopic approach, that is, 28 out of 37 centers (78\%) limited the procedure to left lateral segmentectomy and partial resection of the peripheral lesion. On the other hand, this study also implies that the indications for the laparoscopic approach would expand in the near future. More than half of the centers that limited the laparoscopic procedure to left lateral segmentectomy and partial resection were willing to expand the indication to major hepatectomies. In addition, two-thirds of all centers answered that the application of the laparoscopic approach to donor hepatectomy would be feasible. However, donor mortality is not zero even in open living donor hepatectomies [40]. Hence, one should remain cautious about the application of the laparoscopic approach, whose safety has not been well established regarding major hepatectomy.

Despite the introduction of many devices, a conservative trend was observed regarding the methods to transect the liver parenchyma during open surgery. The clamp-crushing technique and ultrasonic dissectors (CUSA), which were introduced in the 1970s [8] and in the 1990s [9, 10], respectively, were the two major methods favored in many centers. Furthermore, more than half of the centers selected ligation with stitch to seal the thin portal pedicles. Those results might have arisen from the evidence that several randomized trials showed no superiority of other new techniques over classical clamp-crushing [9-15].

A potential selection bias of the centers should be taken into account when interpreting our study results. Asian centers accounted for $69 \%$ of the centers that participated in this survey, and the rate is considerably high compared to the previous survey conducted in 2007 (17\%) [7]. This regional bias must have led to the high application of ICGR15, which is not widely accepted in Western countries [7]. In addition, the low response rate to the questionnaire (45\%) is another limitation of this survey considering the high response rate of the previous survey (75\%). A more organized survey through an international liver association could provide a better overview of the current practices in liver surgery, which would help to make liver surgery safer and more standardized in the near future.

\section{Acknowledgement}

The authors would like to thank all the participants and the centers in the survey (in alphabetic order): Abdalla, Eddie K. from Lebanese American University; Adam, Rene from Paul Brousse Hospital; Azoulay, Daniel from Henri Mondor Hospital; Belghiti, Jacques from Beaujon Hospital; Beppu, Toru from 


\section{Liver Cancer}

\begin{tabular}{l|l}
\hline \multicolumn{2}{l}{ Liver Cancer 2013;2:55-66 } \\
\hline DOI: 10.1159/000346225 7, & $\begin{array}{l}\text { ( } 2013 \text { S. Karger AG, Basel } \\
\text { www.karger.com/lic }\end{array}$ \\
Published online: January 7, 2013 &
\end{tabular}

Mise et al.: A Worldwide Survey of the Current Daily Practice in Liver Surgery

Kumamoto University; Busuttil, Ronald W. from University of California Medical Center; Cappussotti, Lorenzo from Ospedale Mauriziano Umberto; Clavien, Pierre Alain from University of Zurich; Eguchi, Susumu from Nagasaki University; Ku, Yonson from Kobe University; Gumbs, Andrew from Summit Medical Group; Halkic, Nermin from Center Hospitalier Universitaire Vaudois; Han, Ho Seong from Seoul National University Hospital; Honda, Goro from Tokyo Metropolitan Cancer and Infectious Disease Center Komagome Hospital; Ikai, Iwao from Kyoto Medical Center; Kaneko, Hironori from Toho University School of Medicine; Kim, Hong Jin from Yeungham University Hospital; Kimura, Wataru from Yamagata University; Kubota, Keiichi from Dokkyo Medical University; Lee, Seung Gyu from University of Ulsan College of Medicine; Lerut, Jan P. from Center Hospitalier Universitaire Vaudois; Makuuchi, Masatoshi from Japan Red Cross Medical Center; Nagano, Hiroaki from Osaka University; Nagino, Masato from Nagoya University; Nuzzo, Gennaro from Catholic University; Ohkouchi, Nobuhiro from Tsukuba University; Ohtsubo, Takehito from St. Marianna University; Saiura, Akio from Cancer Institute Hospital of JFCR; Sano, Keiji from Teikyo University School of Medicine; Shirabe, Ken from Kyusyu University; Suh, Kyung Suk from Seoul National University Hospital; Takayama, Tadatoshi from Nihon University School of Medicine; Torzilli, Guido from University of Milan; Uemoto, Shinji from Kyoto University; Vauthey, Jean Nicolas from The University of Texas MD Anderson Cancer Center; Wakabayashi, Go from Iwate Medical University School of Medicine; $\mathrm{Wu}$, Cheng Chung from Cung Shan Medical University; Yamamoto, Junji from National Defense Medical College; Yamamoto, Masakazu from Tokyo Women's Medical University; Yamamoto, Yuzou from Akita University, and Yanaga, Katsuhiko from The Jikei University, who contributed to the present survey by replying precious data.

\section{Conflict of Interest}

No conflicts of interest to disclose.

\section{References}

1 Child CG: The Liver and Portal Hypertension. Philadelphia, Saunders, 1964, p 231.

- 2 Malinchoc M, Kamath PS, Gordon FD, Peine CJ, Rank J, ter Borg PC: A model to predict poor survival in patients undergoing transjugular intrahepatic portosystemic shunts. Hepatology 2000;31:864-871.

- 3 Imamura H, Sano K, Sugawara Y, Kokudo N, Makuuchi M: Assessment of hepatic reserve for indication of hepatic resection: decision tree incorporating indocyanine green test. J Hepatobiliary Pancreat Surg 2005; 12:16-22.

4 Makuuchi M, Kosuge T, Takayama T, Yamazaki S, Kakazu T, Miyagawa S, Kawasaki S: Surgery for small liver cancers. Semin Surg Oncol 1993;9:298-304.

5 Torzilli G, Donadon M, Marconi M, Palmisano A, Del Fabbro D, Spinelli A, Botea F, Montorsi M: Hepatectomy for stage $\mathrm{B}$ and stage $\mathrm{C}$ hepatocellular carcinoma in the Barcelona Clinic Liver Cancer classification: results of a prospective analysis. Arch Surg 2008;143:1082-1090.

6 Cescon M, Cucchetti A, Grazi GL, Ferrero A, Vigano L, Ercolani G, Zanello M, Ravaioli M, Capussotti L, Pinna AD: Indication of the extent of hepatectomy for hepatocellular carcinoma on cirrhosis by a simple algorithm based on preoperative variables. Arch Surg 2009;144:57-63, discussion 63.

7 Breitenstein S, Apestegui C, Petrowsky H, Clavien PA: 'State of the art' in liver resection and living donor liver transplantation: a worldwide survey of 100 liver centers. World J Surg 2009;33:797-803.

8 Lin TY: A simplified technique for hepatic resection: the crush method. Ann Surg 1974;180:285-290.

- 9 Rau HG, Wichmann MW, Schinkel S, Buttler E, Pickelmann S, Schauer R, Schildberg FW: Surgical techniques in hepatic resections: ultrasonic aspirator versus Jet-Cutter. A prospective randomized clinical trial (in German). Zentralbl Chir 2001;126:586-590.

-10 Takayama T, Makuuchi M, Kubota K, Harihara Y, Hui AM, Sano K, Ijichi M, Hasegawa K: Randomized comparison of ultrasonic vs clamp transection of the liver. Arch Surg 2001;136:922-928.

$\checkmark 11$ Arita J, Hasegawa K, Kokudo N, Sano K, Sugawara Y, Makuuchi M: Randomized clinical trial of the effect of a saline-linked radiofrequency coagulator on blood loss during hepatic resection. Br J Surg 2005;92:954959.

12 Koo BN, Kil HK, Choi JS, Kim JY, Chun DH, Hong YW: Hepatic resection by the Cavitron Ultrasonic Surgical Aspirator increases the incidence and severity of venous air embolism. Anesth Analg 2005;101:966-970.

-13 Lesurtel M, Selzner M, Petrowsky H, McCormack L, Clavien PA: How should transection of the liver be performed? A prospective randomized study in 100 consecutive patients: comparing four different transection strategies. Ann Surg 2005;242:814-822, discussion 822-823. 
Lupo L, Gallerani A, Panzera P, Tandoi F, Di Palma G, Memeo V: Randomized clinical trial of radiofrequencyassisted versus clamp-crushing liver resection. Br J Surg 2007;94:287-291.

15 Ikeda M, Hasegawa K, Sano K, Imamura H, Beck Y, Sugawara Y, Kokudo N, Makuuchi M: The vessel sealing system (LigaSure) in hepatic resection: a randomized controlled trial. Ann Surg 2009;250:199-203.

16 Pringle JH: V. Notes on the arrest of hepatic hemorrhage due to trauma. Ann Surg 1908;48:541-549.

17 Makuuchi M, Mori T, Gunven P, Yamazaki S, Hasegawa H: Safety of hemihepatic vascular occlusion during resection of the liver. Surg Gynecol Obstet 1987;164:155-158.

18 Takasaki K, Kobayashi S, Tanaka S, Saito A, Yamamoto M, Hanyu F: Highly anatomically systematized hepatic resection with Glissonean sheath code transection at the hepatic hilus. Int Surg 1990;75:73-77.

19 Belghiti J, Noun R, Malafosse R, Jagot P, Sauvanet A, Pierangeli F, Marty J, Farges O: Continuous versus intermittent portal triad clamping for liver resection: a controlled study. Ann Surg 1999;229:369-375.

20 Bismuth H, Castaing D, Garden OJ: Major hepatic resection under total vascular exclusion. Ann Surg 1989; 210:13-19.

-21 Belghiti J, Marty J, Farges 0: Techniques, hemodynamic monitoring, and indications for vascular clamping during liver resections. J Hepatobiliary Pancreat Surg 1998;5:69-76.

22 Cherqui D, Malassagne B, Colau PI, Brunetti F, Rotman N, Fagniez PL: Hepatic vascular exclusion with preservation of the caval flow for liver resections. Ann Surg 1999;230:24-30.

23 Smyrniotis VE, Kostopanagiotou GG, Gamaletsos EL, Vassiliou JG, Voros DC, Fotopoulos AC, Contis JC: Total versus selective hepatic vascular exclusion in major liver resections. Am J Surg 2002;183:173-178.

24 Cole DJ, Ferguson CM: Complications of hepatic resection for colorectal carcinoma metastasis. Am Surg 1992;58:88-91.

-25 Sitzmann JV, Greene PS: Perioperative predictors of morbidity following hepatic resection for neoplasm. A multivariate analysis of a single surgeon experience with 105 patients. Ann Surg 1994;219:13-17.

-26 Yamamoto J, Kosuge T, Takayama T, Shimada K, Yamasaki S, Ozaki H, Yamaguchi N, Mizuno S, Makuuchi M: Perioperative blood transfusion promotes recurrence of hepatocellular carcinoma after hepatectomy. Surgery 1994;115:303-309.

-27 Nakajima Y, Shimamura T, Kamiyama T, Matsushita M, Sato N, Todo S: Control of intraoperative bleeding during liver resection: analysis of a questionnaire sent to 231 Japanese hospitals. Surg Today 2002;32: 48-52.

28 Kubota K, Makuuchi M, Kusaka K, Kobayashi T, Miki K, Hasegawa K, Harihara Y, Takayama T: Measurement of liver volume and hepatic functional reserve as a guide to decision-making in resectional surgery for hepatic tumors. Hepatology 1997;26:1176-1181.

-29 Imamura H, Shimada R, Kubota M, Matsuyama Y, Nakayama A, Miyagawa S, Makuuchi M, Kawasaki S: Preoperative portal vein embolization: an audit of 84 patients. Hepatology 1999;29:1099-1105.

-30 Abdalla EK, Barnett CC, Doherty D, Curley SA, Vauthey JN: Extended hepatectomy in patients with hepatobiliary malignancies with and without preoperative portal vein embolization. Arch Surg 2002;137:675680, discussion 680-681.

-31 Hemming AW, Reed AI, Howard RJ, Fujita S, Hochwald SN, Caridi JG, Hawkins IF, Vauthey JN: Preoperative portal vein embolization for extended hepatectomy. Ann Surg 2003;237:686-691, discussion 691-693.

-32 Abdalla EK, Denys A, Chevalier P, Nemr RA, Vauthey JN: Total and segmental liver volume variations: implications for liver surgery. Surgery 2004;135:404-410.

-33 Vauthey JN, Pawlik TM, Abdalla EK, Arens JF, Nemr RA, Wei SH, Kennamer DL, Ellis LM, Curley SA: Is extended hepatectomy for hepatobiliary malignancy justified? Ann Surg 2004;239:722-730, discussion 730-732.

-34 Imamura H, Seyama Y, Kokudo N, Maema A, Sugawara Y, Sano K, Takayama T, Makuuchi M: One thousand fifty-six hepatectomies without mortality in 8 years. Arch Surg 2003;138:1198-1206, discussion 1206.

-35 Rahbari NN, Koch M, Zimmermann JB, Elbers H, Bruckner T, Contin P, Reissfelder C, Schmidt T, Weigand MA, Martin E, Buchler MW, Weitz J: Infrahepatic inferior vena cava clamping for reduction of central venous pressure and blood loss during hepatic resection: a randomized controlled trial. Ann Surg 2011;253:11021110 .

-36 Zhu P, Lau WY, Chen YF, Zhang BX, Huang ZY, Zhang ZW, Zhang W, Dou L, Chen XP: Randomized clinical trial comparing infrahepatic inferior vena cava clamping with low central venous pressure in complex liver resections involving the Pringle manoeuvre. Br J Surg 2012;99:781-788.

-37 Gagner M, Rogula T, Selzer D: Laparoscopic liver resection: benefits and controversies. Surg Clin North Am 2004;84:451-462.

-38 Simillis C, Constantinides VA, Tekkis PP, Darzi A, Lovegrove R, Jiao L, Antoniou A: Laparoscopic versus open hepatic resections for benign and malignant neoplasms - a meta-analysis. Surgery 2007;141:203-211.

-39 Rao A, Rao G, Ahmed I: Laparoscopic or open liver resection? Let systematic review decide it. Am J Surg 2012;204:222-231.

40 Cheah YL, Simpson MA, Pomposelli JJ, Pomfret EA: The incidence of death and potentially life-threatening 'near miss' events in living donor hepatic lobectomy: a world-wide survey. Liver Transpl 2012, E-pub ahead of print. 